\title{
Proposals for a More Creative Education System
}

\author{
Gina-Maria Moraru ${ }^{1, *}$, and Daniela Popa $^{1}$ \\ 1"'Lucian Blaga" University of Sibiu, Engineering Faculty, Industrial Engineering and Management \\ Department, Emil Cioran Street, No. 4, 550025 Sibiu, Romania
}

\begin{abstract}
The present paper supports the necessity of adapting any modern education system to the growing demand for creative specialists in all fields of activity. In this context, we appreciate that an education system that develops students' creativity can be characterized as a creative system. In the framework of extensive research on creativity management we have developed over the last few years, one of the goals was to discover several ways to improve the education system. From the perspective of educational work in the academic environment, we believe that stimulating student group creativity is essential for their development as future specialists and for their successful integration in organizations. Therefore, we have presented the opinions of a sample of doctoral students and academics regarding the capacity of the Romanian education system to develop group creativity among young people. In order to increase the share of creativity in the education system, the same respondents have suggested several changes in this system. One of the conclusions is that a state that pursues sustainable development should strive to develop the creativity of young people as much as to develop the other skills they need in future jobs.
\end{abstract}

\section{Introduction}

Many labor market studies and forecasts developed by experts around the world show that knowledge- and skill-intensive occupations tend to dominate all industrial branches of the economy, but this is also true for social life sectors [1-4]. Future jobs will mainly require medium- and high-level qualified people [1]. In some regions of the globe there is already a high demand for an educated workforce holding a bachelor's degree or higher [5]. Digital skills will become a priority in the labor markets of the future, as will entrepreneurial skills and creativity [6].

On the other hand, employers are looking for people able to adapt quickly to unforeseen changes and who, in addition to their qualifications, have other skills that add value to organization. [1]

The results of all these studies lead to "the need for continued investment in education and training" and for building "stronger bridges between the worlds of work and education and training" [1].

${ }^{*}$ Corresponding author: gina.moraru@ulbsibiu.ro 


\section{A problem in the business environment caused by the education system}

As we have shown in previous researches related to creativity management, that we have developed in the Romanian industrial environment [7-10], the lack of creativity of young employees with a bachelor's degree is an important problem which managers have to face. Using the problem tree method, we have highlighted the main causes and effects of this issue (Fig. 1).

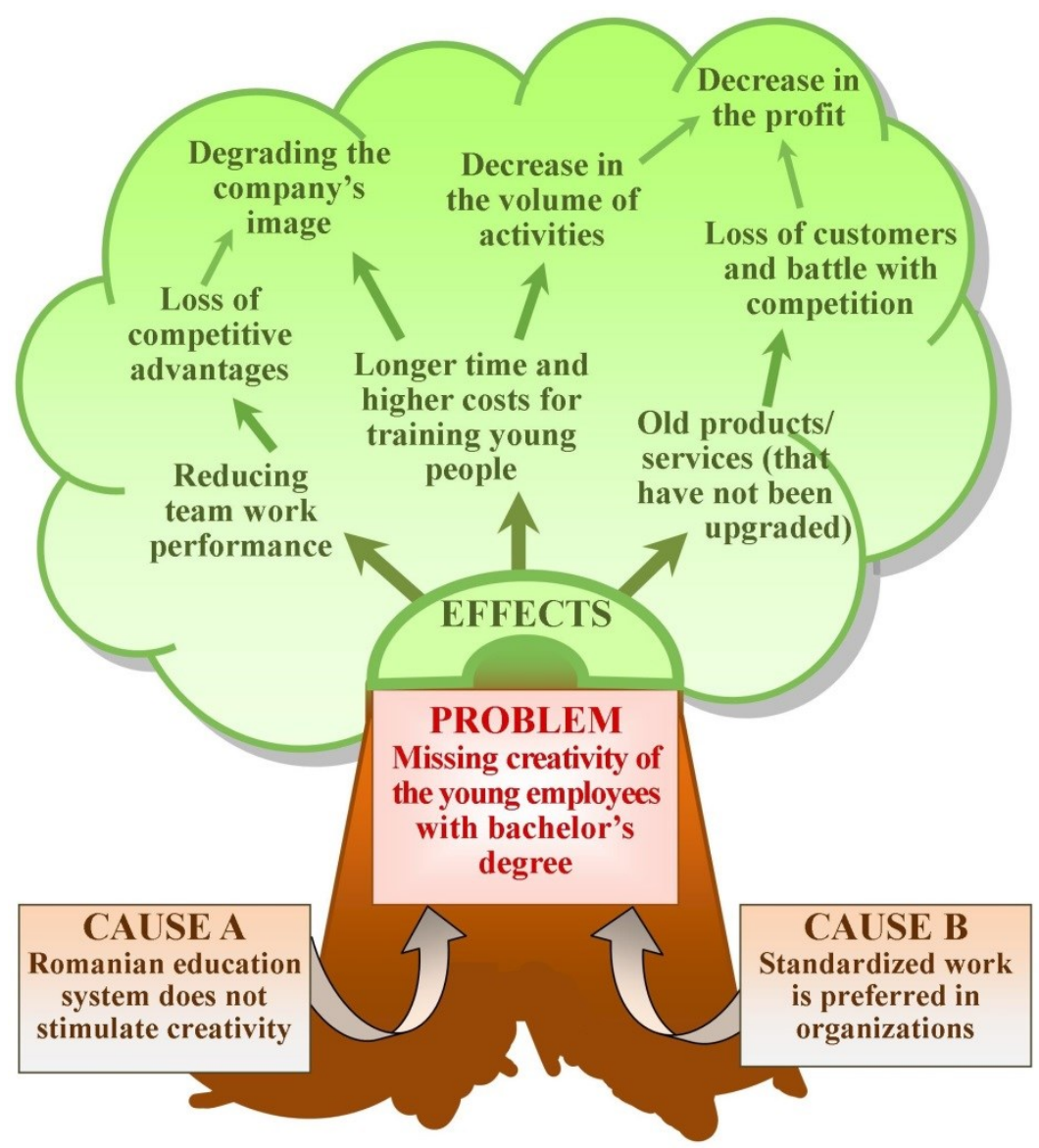

Fig. 1. An important problem for Romanian managers: young employees with bachelor's degree are not creative.

Among undesired effects, we distinguish as more important the degradation of the company's image, the loss of customers and the decrease in the volume of activities and in the profit. Solving this problem and preventing its effects sketched in the crown of the tree are not easy and will probably last for many years, because its main "roots" are very hard to remove (Fig. 1).

The main cause/root A consists in the fact that Romanian education system in general and academic system in particular does not stimulate creativity. This cause can be analyzed by asking the question "why it occurs", thus discovering many indirect causes of the studied problem (Fig. 2).

In the same manner we can analyze the second root of the problem, the cause B (Fig. 1). Standardized work is preferred in many organizations because: 
- Almost all organizations emphasize the adherence to specific field rules, in order to simplify the work processes, their coordination and control.

- The quality demanded by consumers is usually achieved by respecting strict standards and by participating in rigorous audit processes.

- The social environment of organizations, as well as the Romanian environment in general, is still dominated by stereotypes in thinking and reference cadres that reject certain initiatives of creative change in many areas.

Taking into account that the main objective of the paper is to solve the cause A of the problem tree (Fig. 1, 2), cause related to the education system, in the following paragraphs the most important solutions will be mentioned. They were proposed by academics and $\mathrm{PhD}$ students in this respect.

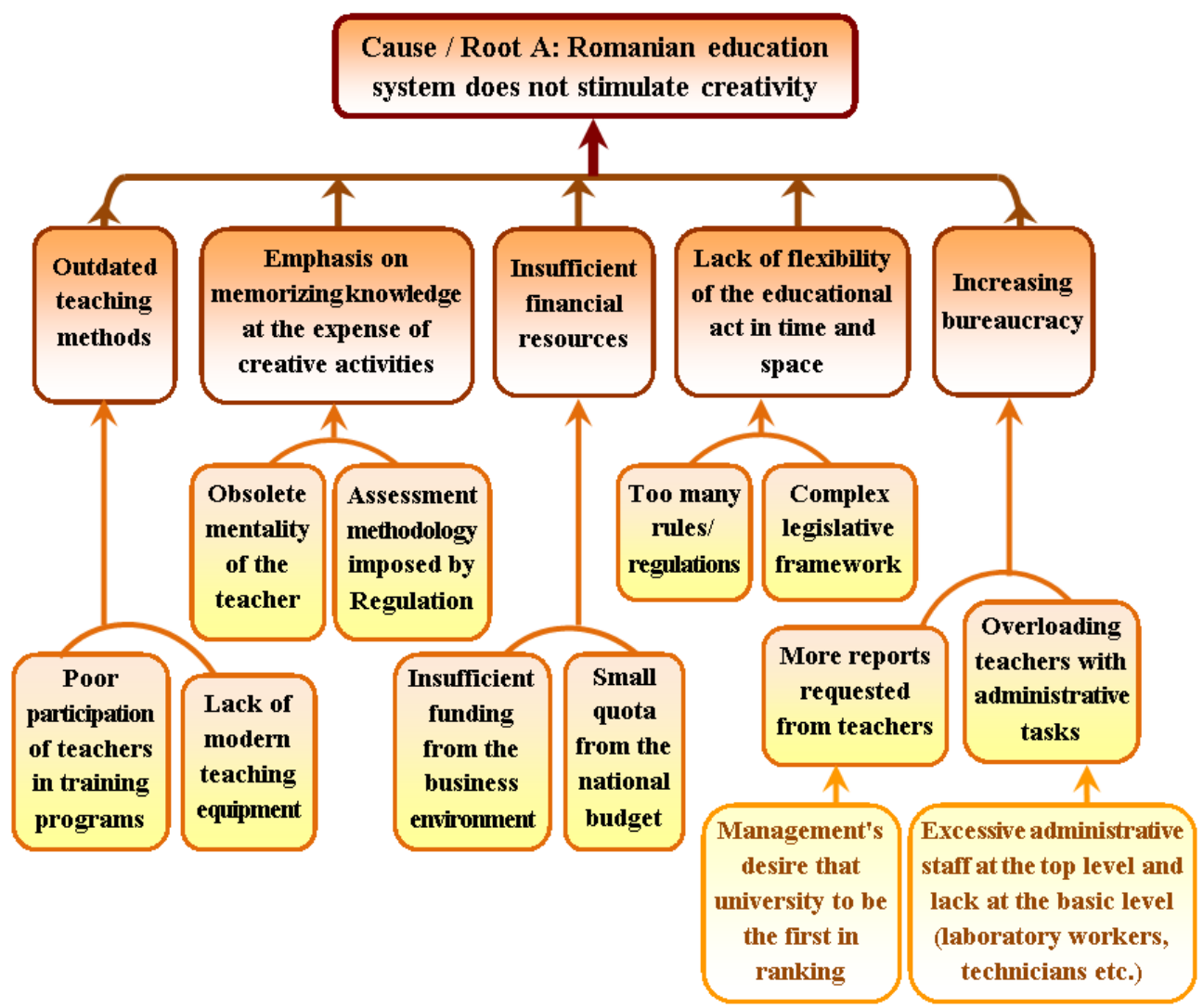

Fig. 2. One of the main causes of the problem: Romanian education system does not stimulate creativity.

\section{Developing group creativity in Romanian education system}

In the framework of extensive research on creativity management we have developed over the last few years, one of the goals was to discover ways to improve the education system. From the perspective of educational work in the academic environment, we believe that stimulating student group creativity is essential for their development as future specialists and for their successful integration in organizations. Therefore, we present the opinions of a 
sample of doctoral students and academics regarding the capacity of the Romanian education system to develop group creativity among young people.

We have evaluated the questions with the following scale: 0 points for the answer "I do not know", 1 point for "no", 2 points for the answer "there is to little extent", 3 points for "there is to some extent", 4 points for "there is to great extent", and 5 points for "there is to very great extent". We have to mention that no one of respondents has chosen the variant "to very great extent" at any question. Answers have been processed using the Microsoft Excel software.

According to the answers received, the student generations lack the training necessary to help them develop their own the group creativity (Fig. 3).

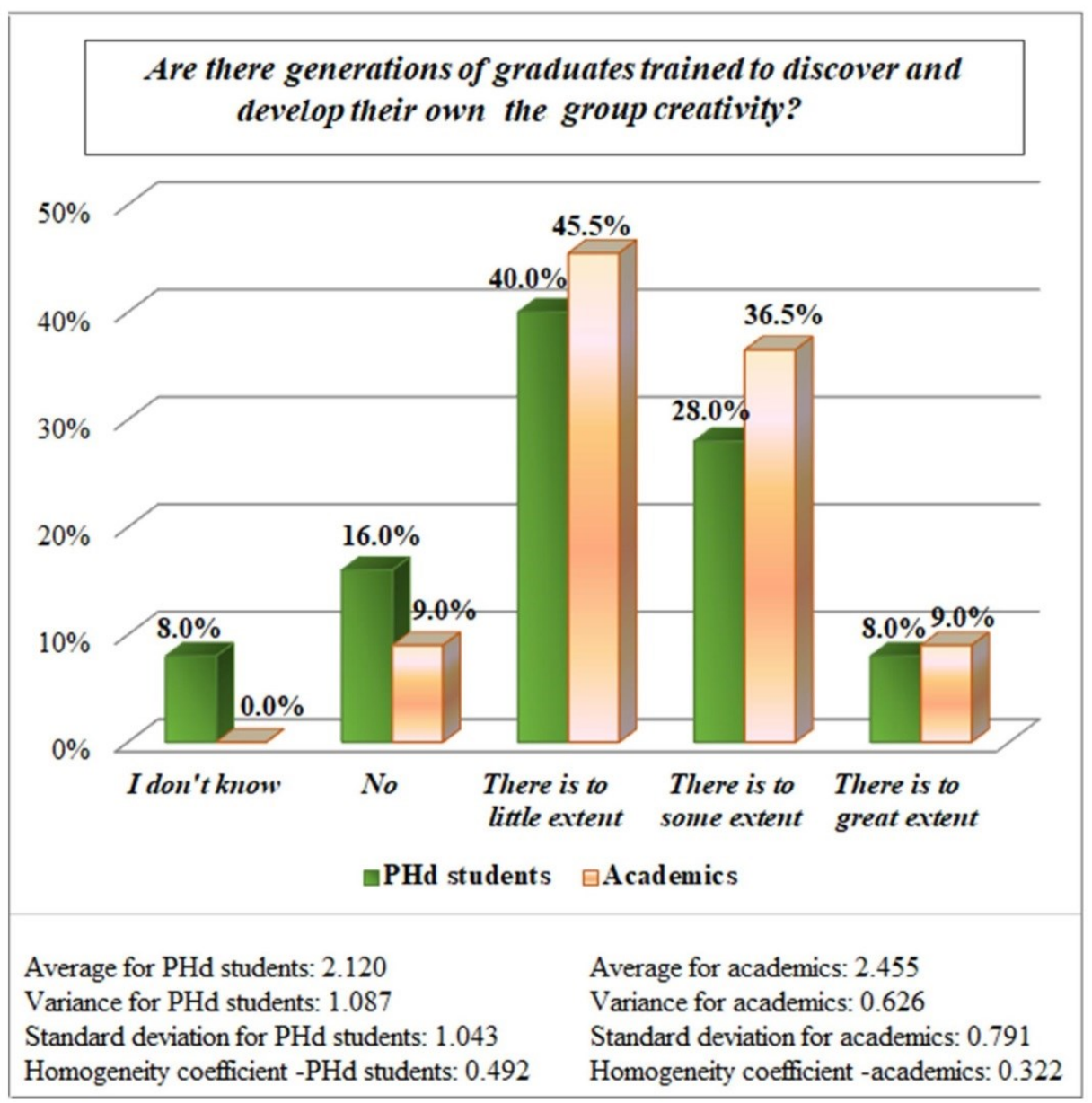

Fig. 3. The capacity of university graduates to develop their own the group creativity.

In order to change this situation, many respondents have proposed:

- Introducing into the academic curriculum some disciplines that stimulate creativity;

- Increasing the share of productive practice in preparing students for the future profession;

- The development of links between faculties with different profiles and the formation of multidisciplinary teams of students;

- Introducing into the teaching regulations the provisions that allow the application of the case study method with effective involvement of students in various problems of partner organizations; 
- Increasing teachers' demand for creative themes, at the expense of typical themes, with solutions at the end of the manual.

The following two questions about possible comparisons between student groups, based on assessing their group creativity (Fig. 4), have had similar results to the answers to the previous question.

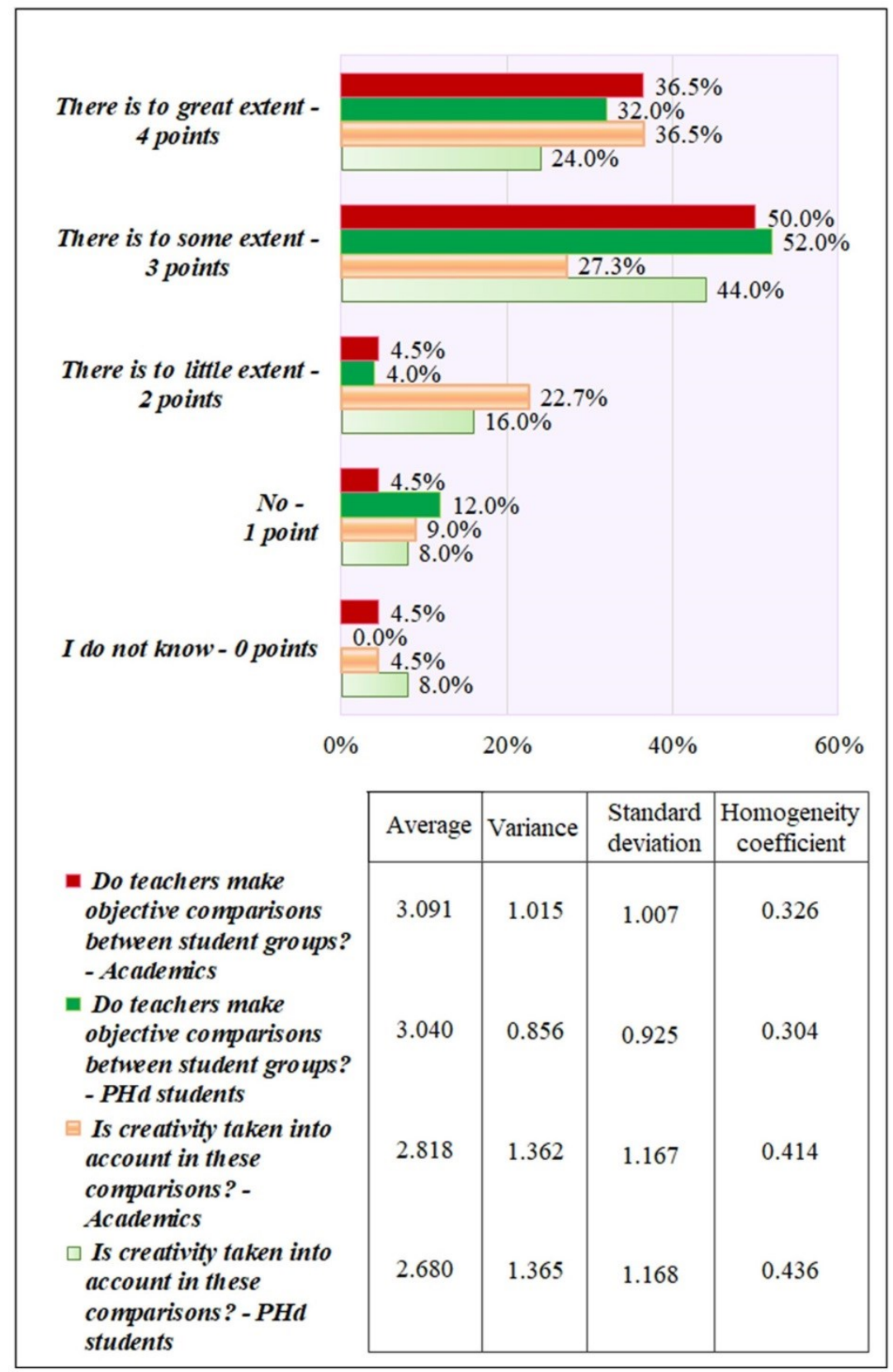

Fig. 4. Romanian teachers rarely make comparisons between student groups and more rarely take into account creativity in these comparisons. 
The most important proposals of respondents at this issue were related to developing the lateral thinking of the students, to changing the way of teaching, as well as the educational norms.

Asked if academics stimulate the competition between student groups, respondents were equally reserved for their appreciation as to the previous questions (Fig. 5).

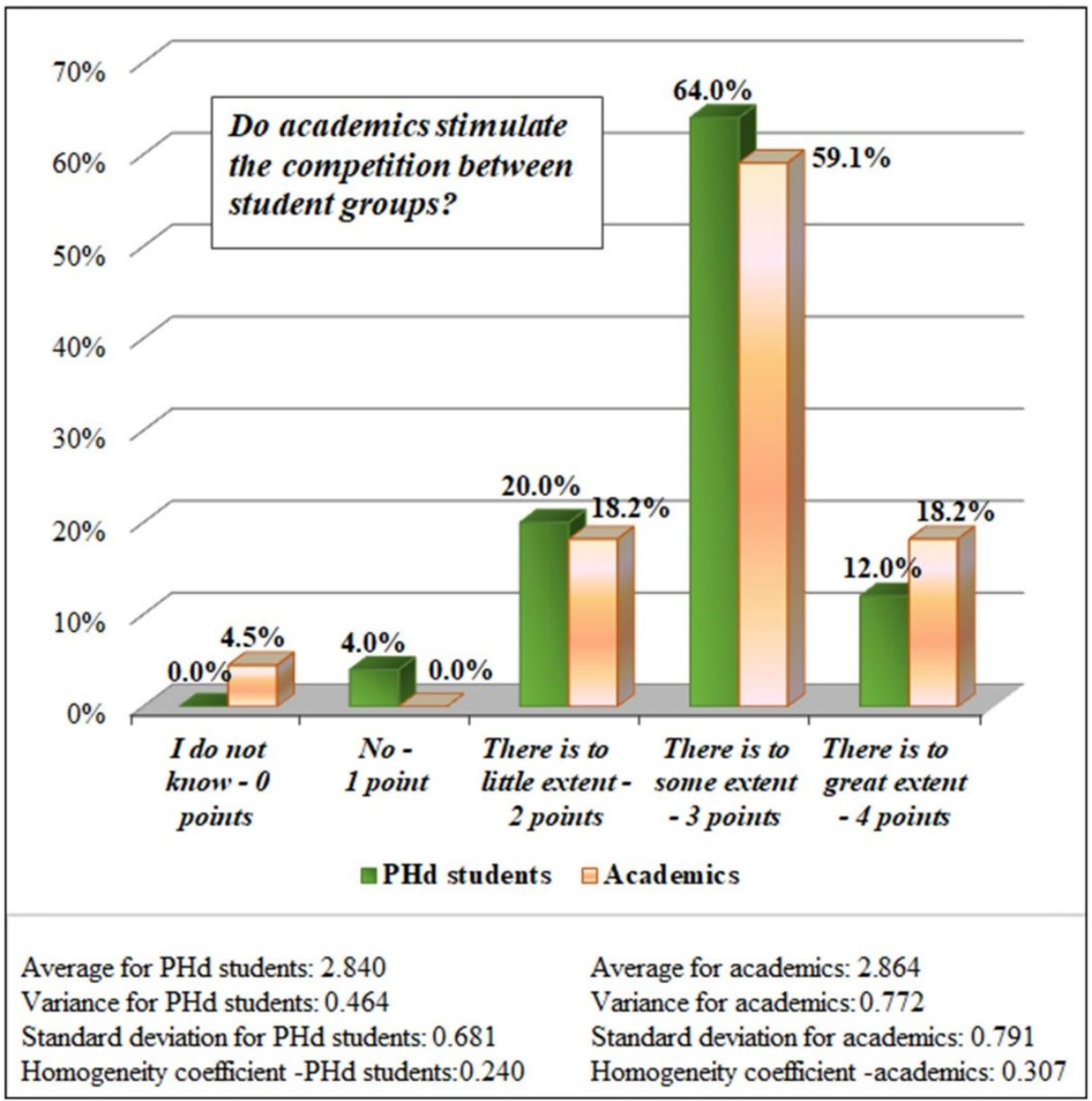

Fig. 5. The competition between student groups is poorly stimulated by Romanian academics.

In order to increase the share of creativity in the education system, respondents have suggested:

- Changing the subjects and study programs, simultaneously with changing the evaluation system of young people;

- Modifying the organizational system of universities basing on national needs;

- Changing the entire informational subsystem of the education system;

- Improving the organizational culture of Romanian universities;

- Finding new financial resources for universities and schools, through commercialization the results of their research.

Many respondents have considered that the involvement of students in university research programs is one of the key mutations required in Romanian academic research. In this sense, some of them have proposed the founding of schools of invention. 
Several responses have highlighted the idea that schools and universities should prepare people for a "learning society".

\section{Conclusions}

In a nutshell, this paper supports the necessity of adapting any modern education system to the growing demand for creative specialists in all fields of activity. An education system that develops students' creativity can be characterized as a creative system.

A state that pursues sustainable development should strive to develop the creativity of young people as much as to develop the other skills they need in future jobs.

\section{References}

1. CEDEFOP, Skills supply and demand in Europe. Medium-term forecast up to 2020 (Publications Office of the EU, Luxembourg, 2010)

2. F. Green, Skills Demand, Training and Skills Mismatch: A Review of Key Concepts, Theory and Evidence, Future of Skills \& Lifelong Learning Evidence Review, Foresight (Government Office for Science, UK, 2016)

3. Universities UK, Supply and demand for higher-level skills, Report (UUK, London, 2015)

4. Charleston Metro Chamber of Commerce, Common Skills in High Demand, Common Skills Competency Report (Charleston, USA, 2016)

5. Commonwealth Corporation, Closing the Skills Gap. Meeting the Demand for Skills in a Growing Economy (2016)

6. W.P. de Groen, K. Lenaerts, R. Bosc, F. Paquier, Impact of digitalisation and the on-demand economy on labour markets and the consequences for employment and industrial relations. Final Study (European Economic and Social Committee, EU, Bruxelles, 2017)

7. G.M. Moraru, International Technology, Education and Development Conference, Proceedings of INTED 2015, 4359-4365 (IATED Academy, Madrid, Spain, 2015)

8. G.M. Moraru, Opportunities to use creativity management in the organizational change and building a sustainable economy ("Lucian Blaga" Univ. of Sibiu Pub., Romania, 2015)

9. G.M. Moraru, 3rd International Multidisciplinary Scientific Conference on Social Sciences and Arts SGEM 2016, Conference Proceedings, 2/3, 815-820 (SGEM, Albena, Bulgaria, 2016)

10. D. Popa, G.M. Moraru, Proceedings of EDULEARN18 Conference, 4198-4203 (IATED Academy, Palma, Mallorca, Spain, 2018) 